\title{
A role for atorvastatin and insulin combination in protecting from liver injury in a model of type 2 diabetes with hyperlipidemia
}

\author{
P. Matafome - E. Nunes - T. Louro - C. Amaral • \\ J. Crisóstomo • L. Rodrigues • A. R. Moedas • \\ P. Monteiro • A. Cipriano • R. Seiça
}

Received: 29 May 2008 / Accepted: 30 September 2008 / Published online: 21 October 2008

(C) Springer-Verlag 2008

\begin{abstract}
Non-alcoholic fatty liver disease (NAFLD) is a major complication linked with the metabolic syndrome associated with dyslipidemia, inflammation, and oxidative stress. Impact of type 2 diabetes with hyperlipidemia in NAFLD has to be established, as well as the utility of commonly prescribed anti-diabetic and lipid-lowering agents in improving liver injury markers. Genetic type 2 diabetic Goto-Kakizaki rats were fed with a high-fat diet to
\end{abstract}

P. Matafome $\cdot$ E. Nunes $\cdot$ T. Louro $\cdot$ C. Amaral - J. Crisóstomo $\cdot$

L. Rodrigues $\cdot$ A. R. Moedas $\cdot$ R. Seiça

Institute of Physiology, Faculty of Medicine,

University of Coimbra,

Coimbra, Portugal

P. Matafome

Center of Ophthalmology, Faculty of Medicine,

University of Coimbra,

Coimbra, Portugal

P. Matafome • T. Louro • C. Amaral · J. Crisóstomo •

L. Rodrigues $\cdot$ R. Seiça

Institute of Biomedical Research in Light and Image,

Faculty of Medicine, University of Coimbra,

Coimbra, Portugal

P. Monteiro

Basic Research Unit in Cardiology, Cardiology Department,

Coimbra University Hospital and Medical School,

Coimbra, Portugal

\section{A. Cipriano}

Serviço de Anatomia Patológica, Coimbra University Hospital, Coimbra, Portugal

\section{P. Matafome $(\bowtie)$}

Faculty of Medicine, Pole III of University of Coimbra,

Subunit 1, 1st floor, Azinhaga de Santa Comba, Celas,

3000-354 Coimbra, Portugal

e-mail: paulomatafome@gmail.com test hepatic effects of type 2 diabetes with hyperlipidemia and the effect of atorvastatin and insulin, individually and in combination, in systemic and hepatic inflammatory and oxidative stress markers. High-fat diet aggravated fasting glycemia, systemic and liver lipids, and inflammatory and oxidative stress markers. Individual treatments improved glycemic and lipid profiles, but failed to improve inflammatory markers, whereas insulin was able to reduce liver oxidative stress parameters. Combination of insulin and atorvastatin further improved glycemic and lipid profiles and decreased circulating C-reactive protein levels and liver inflammatory and oxidative stress markers. Insulin and atorvastatin combination leads to better glycaemic and lipid profiles and to better protection against liver inflammation and oxidative stress, giving a superior level of liver protection in type 2 diabetic with hyperlipidemia.

Keywords Liver - Inflammation - Atorvastatin .

Insulin treatment

$\begin{array}{ll}\text { Abbreviations } \\ \text { NAFLD } & \text { Non-alcoholic fatty liver disease } \\ \text { NASH } & \text { Non-alcoholic steatohepatitis } \\ \text { CRP } & \text { C-reactive protein } \\ \text { TNF- } \alpha & \text { Tumour necrosis factor } \alpha \\ \text { IL-6 } & \text { Interleukin-6 }\end{array}$

\section{Introduction}

In the USA, $20 \%$ of the adults have diagnosed nonalcoholic fatty liver disease (NAFLD) and 2-3\% develops non-alcoholic steatohepatitis (NASH; Cave et al. 2007). NAFLD, which is currently understood as the liver 
expression of the metabolic syndrome, is considered when triglycerides drops occupy more than $5 \%$ of the hepatocyte (Maeda et al. 2005; Neushwander-Tetri 2005). Subjects with NAFLD currently have more visceral fat, insulin resistance, higher levels of C-reactive protein (CRP), free fatty acids (FFA), triglycerides and oxidative stress markers, and lower levels of HDL-cholesterol (Brownlee 2005; Bugianesi et al. 2005a, b; Hanley et al. 2005).

Insulin resistance was reported to be significantly correlated with NAFLD; previous reports showed that normal but not genetic type 2 diabetic Goto-Kakizaki rats subjected to high-fat diet have increased insulin secretion compensating for high-fat-diet-induced insulin resistance (Ota et al. 2007; Shang et al. 2002). Insulin promotes free fatty acids storage in adipocytes and inhibits lipolysis (Bradbury 2006). Hyperlipidemia leads to accumulation of free fatty acids and their metabolites in hepatocytes, which is associated with activation of inflammatory pathways, namely tumor necrosis factor- $\alpha$ (TNF- $\alpha$ ), interleukin-6 (IL-6), and CRP, directly causing insulin resistance (Kaneto et al. 2005; Paumelle et al. 2006; Sethi and Hotamisligil 1999). CRP, in addition to its atherosclerotic effects, severely induces insulin resistance (Yki-Järvinen 2005; Shoelson et al. 2007) and is negatively related with HDLcholesterol levels (Chrysohoou et al. 2006; Pfützner and Forst 2006) and directly with the degree of liver fibrosis (Yoneda et al. 2007)

In obese and type 2 diabetic patients with NASH, adiponectin levels are inversely associated with hepatic steatosis, inflammation, and fibrosis (Meier and Gressner 2004; Yamauchi et al. 2003; Zhou et al. 2005). Furthermore, in normal, but not NASH patients, lipid infusion stimulates adiponectin production (Makowski and Hotamisligil 2005).

Insulin has been widely used among type 2 diabetic patients in order to balance $\beta$ cell failure. Recent standards in medical care suggest insulin therapy in early stages of type 2 diabetes and combination with other therapies, namely statins (Maseri 1995). However, the usefulness of insulin therapy in complications associated with the metabolic syndrome remains to be elucidated.

Atorvastatin is among the most clinically used statins (HMG-CoA reductase inhibitors, a key enzyme of the hepatic cholesterol biosynthesis pathway; Ludwig et al. 2005). Cholesterol produced in the liver incorporates mostly in low-density lipoproteins (LDL), named LDLcholesterol, which directly correlates with atherosclerosis (Bisgaier et al. 1997; Davidson 2005). It has been suggested that statins have acute anti-inflammatory properties, promoting fatty acid oxidation; however, the effects of chronic statin therapy is not entirely established (Planavila et al. 2005). Recent papers have suggested that statin therapy can also have beneficial effects in liver; however, their full extent is not known due to the absence of clinical studies in this field (Ekstedt et al. 2007; Georgescu and Georgescu 2007).

In this study, we evaluated the hepatic effects of high-fat diet in Goto-Kakizaki rats, a spontaneous animal model of type 2 diabetes, and the effects of atorvastatin and insulin, individually and in combination, in this animal model in a young age. Our aim was to assess whether the simultaneous use of atorvastatin and insulin has positive impacts, beyond their individual effects, in liver inflammation and oxidative stress.

\section{Materials and methods}

\section{Reagents}

All compounds were of the purest quality available and were purchased from Sigma Chemical (St. Louis, MO, USA) or Merck (Darmstadt, Germany).

\section{Animals}

Goto-Kakizaki rats, obtained from our local breeding colony (Animal Research Center Laboratory, University Hospital, Coimbra, Portugal), were kept under controlled light $(12 \mathrm{~h} \mathrm{day} / \mathrm{night})$, temperature $\left(22-24^{\circ} \mathrm{C}\right)$, and humidity $(50-60 \%)$ conditions and with free access to water and to standard (Charles River) or to high-fat diet [special diet 0125 (modified A04 from Charles River) SAFE, France] which is composed of 70\% AO4 standard chow, 7.5\% cocoa butter, and $1.25 \%$ cholesterol.

Rats were divided into five experimental groups $(n=12$ per group): one group (SD) maintained with standard diet until 6 months of age and four groups maintained with high-fat diet between 2 and 6 months of age. The high-fat groups were divided according to the treatment [no treatment (AD); insulin (ADI); atorvastatin (ADA); atorvastatin and insulin (ADAI)]. The experimental protocol was approved by the local Institutional Animal Care and Use Committee.

\section{Treatment administration}

Insulin and atorvastatin were administered during the last month (between 5 and 6 months of age). Insulin (Mixtard 30 Novolet, from Novo Nordisk A/S, Denmark) was administered twice a day subcutaneously according to glucose levels: glycemia between 150 and $199 \mathrm{mg} / \mathrm{ml}$, $2 \mathrm{U}$ of insulin; glycemia between 200 and $299 \mathrm{mg} / \mathrm{dl}$, $4 \mathrm{U}$; glycemia higher than $300 \mathrm{mg} / \mathrm{dl}-6 \mathrm{U}$. Atorvastatin (Pfizer, USA) was administered orally $\left(10 \mathrm{mg} \mathrm{kg}^{-1} \mathrm{day}^{-1}\right)$, diluted in water (equivalent to the maximum human dose, $40 \mathrm{mg} /$ day). 
Sample collection and storage

At the end of the treatment (6 months), rats were placed in metabolic boxes for $24 \mathrm{~h}$ and urine was collected. Urine was centrifuged $2000 \times \mathrm{g}, 10 \mathrm{~min}, 4^{\circ} \mathrm{C}$ and stored at $-80^{\circ} \mathrm{C}$.

In another day, blood samples were collected after an overnight fasting by cardiac puncture from anesthetized animals [ketamine chloride $(75 \mathrm{mg} / \mathrm{kg}$, im, Parke-Davis, Ann Arbor, MI, USA) and chlorpromazine chloride $(2.65 \mathrm{mg} / \mathrm{kg}$, im, Lab. Vitória, Portugal)]. For plasma and serum parameters determination, blood was centrifuged $(2,500 \mathrm{rpm}), 10 \mathrm{~min}, 4^{\circ} \mathrm{C}$, aliquoted, and stored at $-20^{\circ} \mathrm{C}$. Animals were killed by cervical dislocation and livers were immediately collected and briefly washed in $\mathrm{NaCl}(0.9 \%)$. Liver sections from ten animals per group were fixed in $10 \%$ buffered formalin and embedded in paraffin for histological analysis. Remaining tissue was frozen in liquid nitrogen and stored at $-80^{\circ} \mathrm{C}$.

Blood glucose and plasma insulin levels

Blood glucose levels, fasting and $2 \mathrm{~h}$ after glucose load $(1.8 \mathrm{~g} / \mathrm{kg})$, were determined through the glucose oxidase method using a glucometer (Elite-Bayer, Portugal). Plasma insulin was determined by an in-house competitive enzyme-linked immunosorbent assay (ELISA) as previously described (Nunes et al. 2007; Seiça et al. 2004). Immunoglobulin G-certified microtiter plates (96 wells, Nunc, Roskilde, Denmark) were incubated overnight at $4^{\circ} \mathrm{C}$, with guinea pig-rat insulin serum (Biotrend Chemikalien, $\mathrm{GmbH}$ ) using rat insulin as standard (Linco Research Inc, USA). 3,3', 5,5'-tetrametilbenzidine (TMB, liquid substrate system; Sigma Chemicals) was used as substrate for the insulin-peroxidase conjugate, and the reaction product was assayed spectrophotometrically (450 nm; Gen5, Biotek Instruments, USA) after a 30-min incubation with TMB at room temperature (the reaction was stopped with sulfuric acid).

Insulin resistance was measured through the homeostasis model assessment (HOMA) index and the quantitative insulin sensitivity index (QUICKI). HOMA was calculated as $\left[\left(I_{\mathrm{f}}\right) \times\left(G_{\mathrm{f}}\right)\right] / 22.5$, where $\left(I_{\mathrm{f}}\right)$ is the fasting insulin level $(\mu \mathrm{U} / \mathrm{ml})$ and $\left(G_{\mathrm{f}}\right)$ is the fasting glucose level $(\mathrm{mmol} / \mathrm{L}$; Chen et al. 2005). QUICKI was calculated as $1 /\left[\log \left(G_{0}\right)+\right.$ $\left.\log \left(I_{0}\right)\right]$, where $G_{0}$ is fasting glucose $(\mathrm{mg} / \mathrm{dL})$ and $I_{0}$ is fasting insulin ( $\mu \mathrm{U} / \mathrm{ml}$; Chen et al. 2005).

\section{Circulating and liver lipids}

Serum triglycerides and cholesterol (total and HDL) and liver triglycerides and cholesterol levels were determined using commercial kits (Olympus-Diagnóstica Portugal, Produtos de Diagnóstico SA, Portugal). Atherogenicity index (A.I.) was calculated as total cholesterol/HDLcholesterol. Plasma free fatty acid levels were determined using the half-micro test, Roche Diagnostic, Germany.

For liver lipid content determination, liver sections $(1.25 \mathrm{~g})$ were homogenized in $7.5 \mathrm{ml}$ chloroform/methanol $(2: 1, v / v)$ solution and vortexed during $15 \mathrm{~min}$. Chloroform $(2.5 \mathrm{ml})$ and ultra pure water $(2.5 \mathrm{ml})$ were added and homogenates were centrifuged at $3,000 \mathrm{rpm}, 8 \mathrm{~min}, 4^{\circ} \mathrm{C}$. The lower (chloroform) phase was collected in a clean tube. In the first tube, $3.76 \mathrm{ml}$ of chloroform was added. Samples were vortexed and centrifuged at $3,000 \mathrm{rpm}, 8 \mathrm{~min}, 4^{\circ} \mathrm{C}$. Chloroform phase was collected and added to chloroform phase from first centrifugation. Samples were evaporated at $55^{\circ} \mathrm{C}$ under nitrogen atmosphere and suspended in $2 \mathrm{ml}$ of 2-propanol for lipid measure.

\section{Inflammatory markers}

Serum C-reactive protein levels were measured using the Creactive protein ELISA kit, and circulating and hepatic TNF- $\alpha$ and IL- 6 levels were determined by the rat TNF ELISA set and rat IL-6 ELISA set, respectively (BD Biosciences Pharmingen, CA, USA). Serum levels of adiponectin were quantified by the ELISA Phoenix adiponectin kit assay (Phoenix, USA). Liver sections (200 mg) were homogenized in $2 \mathrm{ml}$ of cold $25 \mathrm{mM}$ Tris- $\mathrm{HCl}$ buffer containing $100 \mathrm{mM} \mathrm{NaCl}, 1 \mathrm{mM}$ EDTA, $1 \mathrm{mM}$ EGTA, $1 \%$ Triton X-100, $10 \mathrm{mM}$ PMSF and protease inhibitors cocktail, $\mathrm{pH}=7.4$. Homogenates were centrifuged at $14,000 \mathrm{rpm}, 20 \mathrm{~min}, 4^{\circ} \mathrm{C}$. Supernatant was transferred to a clean tube and centrifuged at $14,000 \mathrm{rpm}, 15 \mathrm{~min}, 4^{\circ} \mathrm{C}$. Supernatant was collected, aliquoted, and stored at $-80^{\circ} \mathrm{C}$.

\section{Oxidative stress markers}

Plasma and liver carbonyl protein concentration was determined using the protein carbonyl assay (Cayman Chemical Company, USA). Liver was homogenized in cold buffer (50 mM Tris, $150 \mathrm{mM} \mathrm{NaCl}, 1 \mathrm{mM}$ EDTA, $\mathrm{pH}=7.4$ ) and centrifuged at $10,000 \mathrm{rpm}, 15 \mathrm{~min}, 4^{\circ} \mathrm{C}$. Supernatants were stored at $-80^{\circ} \mathrm{C}$.

Urine and liver free 8-isoprostane was determined using the 8-isoprostane EIA assay (Cayman Chemical Company). Liver was homogenized in $0.1 \mathrm{M}$ cold phosphate-buffered solution containing $1 \mathrm{mM}$ EDTA and $10 \mu \mathrm{M}$ indomethacin and was stored at $-80^{\circ} \mathrm{C}$ according to the manufacturer's instructions.

Histological analysis

The 4- $\mu \mathrm{m}$-thick paraffinized liver sections were deparaffinized with xylene and rehydrated through decreasing concentrations of ethanol for staining with hematoxylin-eosin. 
Statistics

Data are presented as mean \pm SEM. Statistical differences between AD and SD groups were determined by Student's $t$ test. One-way analysis of variance and Tukey multiple comparison test were used to assess differences between treatments. A value of $P<0.05$ was considered statistically significant.

\section{Results}

Body weight and food consumption

High-fat diet significantly increased body weigh $(P<$ $0.001)$. None of the treatments significantly altered this parameter in comparison to $\mathrm{AD}$ group (Table 1). Food consumption was similar in all experimental groups (Table 1).

High-fat diet increases fasting glycemia and aggravates lipid profile

Fasting glycemia was significantly higher in atherogenic diet group than in standard diet group $(P<0.001$; Table 1). Glycemia $2 \mathrm{~h}$ after intraperitoneal glucose administration and insulin resistance indexes were not changed by atherogenic diet (Table 1).

High-fat diet group increased total cholesterol $(P<0.05)$ and reduced HDL-cholesterol circulating levels $(P<0.001)$ when compared with SD group (Table 2). Furthermore, higher A.I. (total/HDL-cholesterol; $P<0.001$ ), triglyceride $(P<0.01)$, and FFA $(P<0.001)$ levels were observed in AD group (Table 2).
Insulin and atorvastatin combination further improve glycemic and lipid profiles

Fasting glycemia was significantly decreased by all treatments $(P<0.001)$. However, atorvastatin resulted in a less pronounced effect than observed in ADI and ADAI $(P<0.001$; Table 1). In relation to $\mathrm{AD}$ group insulin and atorvastatin groups had shown no improvements in glycemia $2 \mathrm{~h}$ after glucose administration; only the combination therapy resulted in significant improvements when compared to $\mathrm{AD}$ $(P<0.001)$, ADI $(P<0.05)$, and ADA $(P<0.01)$ groups (Table 1). When compared with $\mathrm{AD}$ group, atorvastatin treatment significantly improved HOMA $(P<0.05)$ and QUICKI $(P<0.01)$, but a more pronounced effect was observed with insulin and combination treatment in both HOMA $(P<0.01)$ and QUICKI $(P<0.001)$. In QUICKI, combination treatment also showed a significant difference when compared to atorvastatin group $(P<0.05)$, thus further improving insulin sensitivity (Table 1 ).

Treatments did not alter total cholesterol levels in relation to $\mathrm{AD}$ group (Table 2); however, all of them significantly improved HDL-cholesterol levels $(P<0.01$; Table 2). Although HDL-cholesterol was improved in all groups, only the group receiving both insulin and atorvastatin showed a significant decrease in A.I. in comparison to $\mathrm{AD}(P<0.05)$ and ADI groups $(P<0.05$; Table 2$)$. When comparing with high-fat diet group, the triglycerides concentration did not change with the treatments, but all of them significantly decreased fasting free fatty acid levels $(P<0.001$; Table 2).

\section{Liver weight}

Liver weight, expressed as percentage of body weight, was higher in high-fat diet group than in standard diet group

Table 1 Body (g) and liver (\% of body weight) weight, food consumption (grams per rat per day), glycemia (mmol/L), fasting and $2 \mathrm{~h}$ after intraperitoneal glucose administration $(1.8 \mathrm{~g} / \mathrm{kg})$, and insulin resistance indexes

\begin{tabular}{|c|c|c|c|c|c|}
\hline Parameter & $\mathrm{SD}$ & $\mathrm{AD}$ & ADI & $\mathrm{ADA}$ & ADAI \\
\hline Body weight $(\mathrm{g})$ & $345 \pm 8$ & $387 \pm 17^{\mathrm{a} * * *}$ & $392 \pm 5$ & $401 \pm 7$ & $391 \pm 5$ \\
\hline Diet (grams per rat per day) & $23 \pm 0$ & $19 \pm 2$ & $19 \pm 1$ & $20 \pm 1$ & $18 \pm 1$ \\
\hline$\% \operatorname{Liver}_{\mathrm{W}} /$ body $_{\mathrm{W}}$ & $4.1 \pm 0.1$ & $4.7 \pm 0.2^{\mathrm{a} *}$ & $3.6 \pm 0.1^{\mathrm{b} * * *}$ & $3.5 \pm 0.1^{\mathrm{b} * * *}$ & $3.4 \pm 0.1^{\mathrm{b} * * *}$ \\
\hline Fasting glycemia (mmol/L) & $5.2 \pm 0.1$ & $7.8 \pm 0.2^{\mathrm{a} * * *}$ & $5.4 \pm 0.1^{\mathrm{b}, \mathrm{d}_{* * *}}$ & $6.6 \pm 0.1^{\mathrm{b} * * *}$ & $5.0 \pm 0.1^{\mathrm{b}, \mathrm{d} * * *}$ \\
\hline Glycemia at $2 \mathrm{~h}(\mathrm{mmol} / \mathrm{L})$ & $16.6 \pm 0.4$ & $16.8 \pm 0.8$ & $14.9 \pm 0.8$ & $16.0 \pm 0.6$ & $12.3 \pm 07^{\mathrm{b}, \mathrm{c}, \mathrm{d}^{* * * * *, * *}}$ \\
\hline HOMA & $11.2 \pm 1.3$ & $14.7 \pm 2.5$ & $5.3 \pm 1.0^{\mathrm{b} * *}$ & $7.3 \pm 0.8^{\mathrm{b} *}$ & $4.8 \pm 1.2^{\mathrm{b} * *}$ \\
\hline QUICKI & $0.29 \pm 0.06$ & $0.27 \pm 0.04$ & $0.31 \pm 0.08^{\mathrm{b} * * *}$ & $0.29 \pm 0.05^{\mathrm{b} * *}$ & $0.32 \pm 0.09^{\mathrm{b}, \mathrm{d}^{* * *}, *}$ \\
\hline
\end{tabular}

Data are presented as means \pm SEM

$S D$ standard diet, $A D$ atherogenic diet, $A D I \mathrm{AD}+$ insulin, $A D A \mathrm{AD}+$ atorvastatin, $A D A I \mathrm{AD}+$ atorvastatin plus insulin $(n=12)$

$* P<0.05 ; * * P<0.01 ; * * * P<0.001$

${ }^{\mathrm{a}}$ Represents significant differences from SD group

${ }^{\mathrm{b}}$ Represents a significant difference from the AD group

${ }^{\mathrm{c}}$ Represents a significant difference from insulin group

${ }^{\mathrm{d}}$ Represents significant differences from atorvastatin group 
Table 2 Total and HDL-cholesterol (mg/dL), atherogenicity index (AI), triglycerides (mg/dL), plasma FFAs (mM), and adiponectin levels ( $\mu \mathrm{g} / \mathrm{ml})$

\begin{tabular}{|c|c|c|c|c|c|}
\hline Parameter & SD & $\mathrm{AD}$ & ADI & $\mathrm{ADA}$ & ADAI \\
\hline Total cholesterol (mg/dL) & $88.9 \pm 1.9$ & $100.4 \pm 5.3^{\mathrm{a} *}$ & $105.1 \pm 3.9$ & $116.4 \pm 8.1$ & $96.5 \pm 4.3^{\mathrm{d} *}$ \\
\hline HDL-cholesterol (mg/dL) & $61.4 \pm 1.3$ & $48.8 \pm 0.9^{\mathrm{a} * * *}$ & $53.7 \pm 1.0^{\mathrm{b} * *}$ & $59.4 \pm 2.6^{\mathrm{b} * *}$ & $55.3 \pm 1.7^{\mathrm{b} * *}$ \\
\hline A.I. & $1.45 \pm 0.01$ & $2.02 \pm 1.01^{\mathrm{a} * * *}$ & $1.96 \pm 0.06$ & $1.87 \pm 0.05$ & $1.74 \pm 0.04^{\mathrm{b}, \mathrm{d} *}$ \\
\hline Triglycerides (mg/dL) & $149.5 \pm 11.6$ & $222.9 \pm 20^{\mathrm{a} * *}$ & $193.7 \pm 8.5$ & $271.7 \pm 23$ & $196.4 \pm 12.2$ \\
\hline FFA $(\mathrm{mM})$ & $0.79 \pm 0.04$ & $1.13 \pm 0.04^{\mathrm{a} * * *}$ & $0.79 \pm 0.06^{\mathrm{b} * * *}$ & $0.81 \pm 0.07^{\mathrm{b} * * *}$ & $0.69 \pm 0.06^{\mathrm{b} * * *}$ \\
\hline Adiponectin $(\mu \mathrm{g} / \mathrm{ml})$ & $4.6 \pm 0.3$ & $5.2 \pm 0.3$ & $6.1 \pm 0.6^{\mathrm{d}^{* * *}}$ & $3.3 \pm 0.2^{\mathrm{b} * * *}$ & $4.9 \pm 0.4^{\mathrm{d}^{* * *}}$ \\
\hline
\end{tabular}

Data are presented as means \pm SEM

$S D$ standard diet, $A D$ atherogenic diet, $A D I \mathrm{AD}+$ insulin, $A D A \mathrm{AD}+$ atorvastatin, $A D A I \mathrm{AD}+$ atorvastatin plus insulin $(n=12)$

$* P<0.05 ; * * P<0.01 ; * * * P<0.001$

${ }^{\text {a }}$ Represents significant differences from SD group

${ }^{\mathrm{b}}$ Represents significant difference from the AD group

${ }^{\mathrm{c}}$ Represents significant difference from insulin group

${ }^{\mathrm{d}}$ Represents significant difference from atorvastatin group

$(P<0.05)$. All treatments prevented liver hypertrophy observed in $\mathrm{AD}$ group $(P<0.001$; Table 1$)$.

Treatments fail to improve high-fat diet-induced lipid accumulation in liver

Liver cholesterol $(P<0.001)$ and triglycerides $(P<0.001)$ levels were significantly increased by high-fat diet. Treatments were not able to improve these parameters (Fig. 1a,b).

High-fat diet aggravates systemic and hepatic inflammatory status

High-fat diet did not result in significant adiponectin alterations (Table 2), but significantly increased CRP circulating levels in relation to standard diet-fed rats $(P<$ 0.05 ; Fig. 2a). Circulating TNF- $\alpha$ and IL-6 levels were also measured, but these values were below the detection limit in all experimental groups (TNF- $\alpha<15.6 \mathrm{pg} / \mathrm{ml}$; IL- $6<$ $39 \mathrm{pg} / \mathrm{ml}$ ), thus suggesting that is not an issue in this model.

Liver TNF- $\alpha$ and IL- 6 concentrations were determined as markers of liver inflammation. Atherogenic diet signif- icantly increased both cytokines concentration in relation to SD group (TNF- $\alpha$ : $P<0.001$; IL-6: $P<0.001$; Fig. $2 \mathrm{~b}, \mathrm{c}$ ).

Combination treatment further improve inflammatory status

Insulin and combination treatment did not significantly alter adiponectinemia (Table 2). Atorvastatin significantly decreased circulating adiponectin levels as compared to $\mathrm{AD}(P<0.001)$ ADI $(P<0.001)$, and ADAI groups $(P<0.001$; Table 2$)$.

Isolated insulin and atorvastatin had no significant effects in circulating CRP and liver TNF- $\alpha$ and IL-6 levels. Only therapy combination significantly improved each of these inflammatory markers $(P<0.05)$ when compared to the $\mathrm{AD}$ group (Fig. 3a-c). There were no observed significant differences between treatments.

High-fat diet increases systemic and hepatic oxidative stress markers

Systemic and liver protein carbonyl and free 8-isoprostane levels were determined as markers of oxidative stress. Our data show that high-fat diet increased systemic protein
Fig. 1 Liver cholesterol and triglycerides levels ( $\mathrm{mg} / \mathrm{g}$ tissue) in standard diet, high-fat diet, and treatments groups. $S D$ standard diet, $A D$ atherogenic diet, $A D I$ insulin, $A D A$ atorvastatin, $A D A I$ atorvastatin plus insulin $(n=8-9$ per group). Data are presented as means \pm SEM. ${ }^{+}$Represents significant differences from SD group $\left({ }^{++} P<0.001\right)$
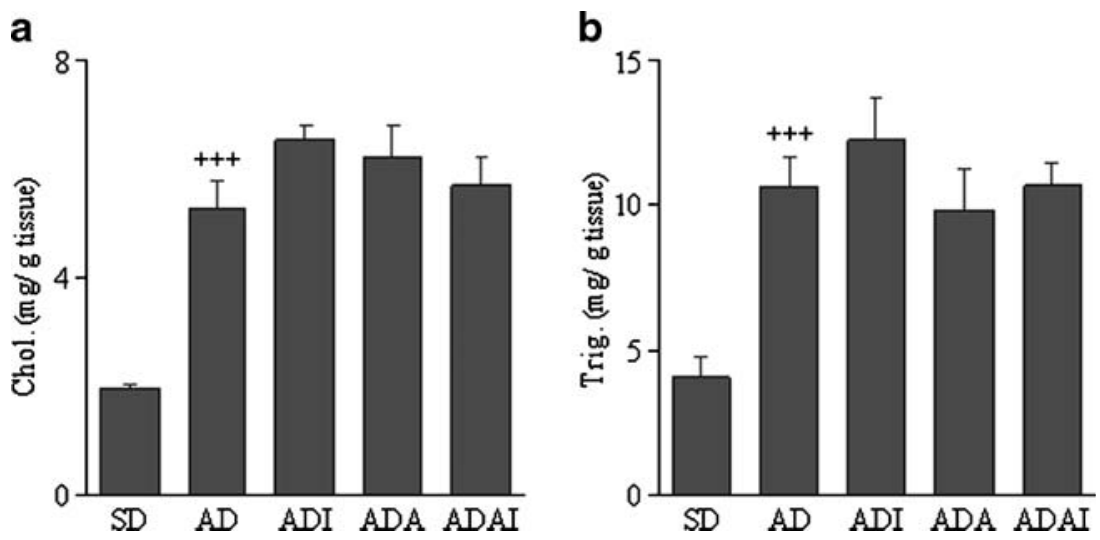
Fig. 2 Circulating CRP concentration $(\mu \mathrm{g} / \mathrm{ml})$ (a) and liver TNF- $\alpha$ (b) and IL-6 (c) concentrations ( $\mathrm{ng} / \mathrm{mg}$ protein) in standard and high-fat diet groups. $S D$ standard diet, $A D$ atherogenic diet $(n=8-9$ per group). Data are presented as means \pm SEM. ${ }^{+}$Represents significant differences from SD group $\left({ }^{+} P<0.05 ;{ }^{+++} P<0.001\right)$

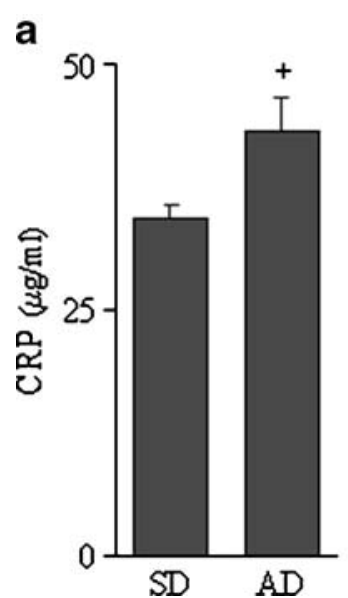

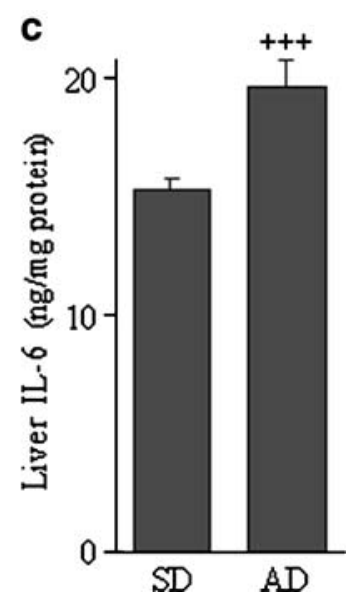

carbonyl levels $(P<0.001)$ and did not significantly alter free 8-isoprostane (Table 3). Liver carbonyl compounds $(P<0.001)$ and free 8 -isoprostane $(P<0.05)$ levels were significantly higher in $\mathrm{AD}$ group when compared to $\mathrm{SD}$ group (Fig. 4a,b).

Combination with atorvastatin enhances insulin effects in decreasing liver oxidative stress

None of the treatments had a significant effect on circulating protein carbonyl compounds and urine free b

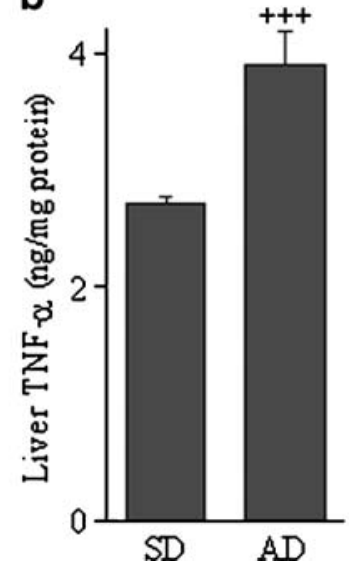

8-isoprostane levels despite an increase in free 8-isoprostane observed with individual atorvastatin treatment $(P<0.05$; Table 3). Atorvastatin showed no effect in liver levels of protein carbonyl and free 8-isoprostane (Fig. 5a,b). Only insulin and its combination with atorvastatin resulted in a significant decrease of both parameters in relation to AD group (P. carbonyl: $P<0.05 ; 8$-isoprostane: $P<0.05$ ) and atorvastatin group in liver protein carbonyl levels $(P<0.05$; Fig. 5a,b). Furthermore, insulin and atorvastatin combination induced a decrease of free 8 -isoprostane in relation to individual atorvastatin $(P<0.05$; Fig. 5b).
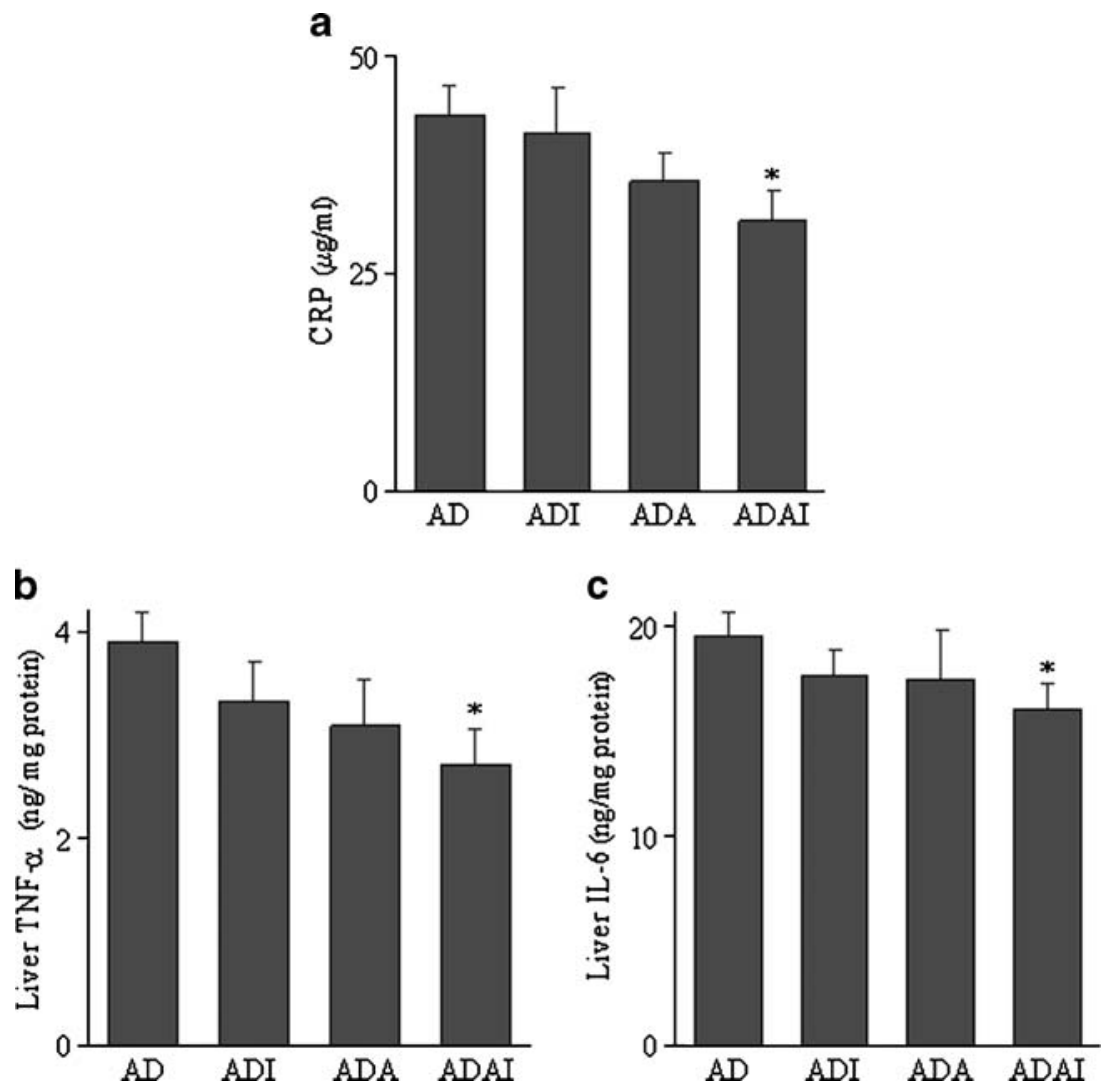
Table 3 Plasma concentration of protein carbonyl (nmol/mL) and free 8-isoprostane in urine in 24 hours (ng/24 hours)

\begin{tabular}{|c|c|c|c|c|c|}
\hline Parameter & $\mathrm{SD}$ & $\mathrm{AD}$ & ADI & ADA & ADAI \\
\hline Prot. carbonyl (nmol/mL) & $23.5 \pm 1.1$ & $38.1 \pm 3.0^{\mathrm{a} * *}$ & $35.8 \pm 3.7$ & $31.0 \pm 2.2$ & $33.8 \pm 2.7$ \\
\hline 8 -Isoprostane $(\mathrm{ng} / 24 \mathrm{~h})$ & $23.1 \pm 2.2$ & $19.7 \pm 1.2$ & $21.8 \pm 2.7$ & $25.5 \pm 1.2^{\mathrm{b} *}$ & $21.2 \pm 4.0$ \\
\hline
\end{tabular}

Data are presented as means \pm SEM

$S D$ standard diet, $A D$ atherogenic diet, $A D I \mathrm{AD}+$ insulin, $A D A \mathrm{AD}+$ atorvastatin, $A D A I \mathrm{AD}+$ atorvastatin plus insulin $(n=8 / 9)$

$* P<0.05 ; * * P<0.001$

${ }^{a}$ Represents significant differences from SD group

${ }^{\mathrm{b}}$ Represents a significant difference from the $\mathrm{AD}$ group

High-fat diet causes portal inflammation

High-fat-fed rats showed an unspecific portal inflammation (Fig. 6b, c) in a very significant range when compared to SD group (Fig. 6a). Hepatic steatosis and fibrosis was not observed at this age.

Combination of insulin and atorvastatin further improves portal inflammation

Individual insulin and atorvastatin (Fig. 7b,c) partially reverted inflammatory process observed in livers of highfat-fed rats (Fig. 7a). However, combination of atorvastatin and insulin enhances the effects observed in each individual treatment (Fig. 7d). In fact, combination treatment reduced portal inflammation almost completely.

\section{Discussion and conclusions}

In this study, we show that high-fat diet aggravates systemic and liver lipid profile and inflammatory and oxidative markers in an animal model of type 2 diabetes. Our data also show that combinatory use of insulin and
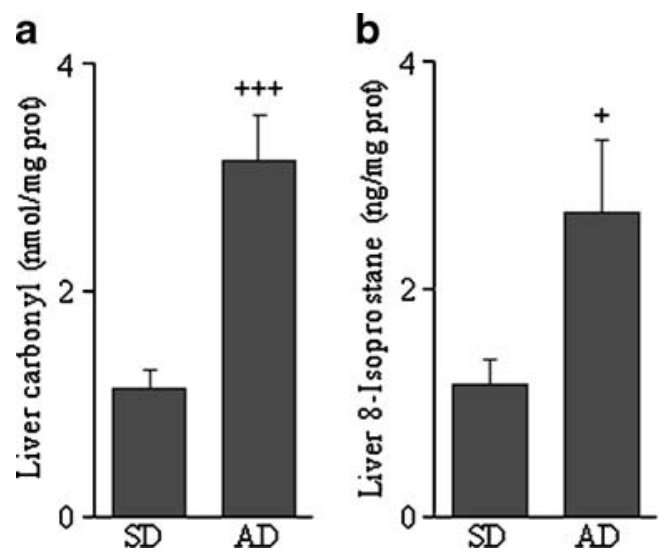

Fig. 4 Liver protein carbonyl (nmol/ $\mathrm{mg}$ protein) (a) and free 8isoprostane (ng/mg protein) (b) concentration in standard and high-fat diet groups. $S D$ standard diet, $A D$ atherogenic diet ( $n=8-9$ per group). Data are presented as means \pm SEM. ${ }^{+}$Represents significant differences from SD group $\left({ }^{+} P<0.05 ;{ }^{++} P<0.001\right)$ atorvastatin improves these parameters beyond the effects of individual therapies, providing superior liver protection in the context of type 2 diabetes and hyperlipidemia.

Atherogenic diet administration increases body and liver weight and aggravates fasting glycemia, total and HDLcholesterol, atherogenicity index, triglycerides, free fatty acids and liver lipids. Although circulating TNF- $\alpha$ and IL-6 were not measurable and significant alterations in adiponectin levels are not seen, liver TNF- $\alpha$ and IL-6 levels and serum CRP levels are increased in this group, suggesting an aggravated systemic and liver inflammatory status. Accordingly, histological analysis shows that despite high-fat diet not resulting in hepatic steatosis, an evident portal inflammation was induced.

A recent study from Grimsrud et al. (2007) showed that obesity and insulin resistance are associated with adipose protein carbonylation. This study identified mechanisms of protein carbonylation responsible for induction of insulin resistance. Our results suggest that these mechanisms can be involved in liver insulin resistance in conditions of hyperlipidemia: High-fat diet increases liver concentration of protein carbonyl and free 8-isoprotane.

Insulin is known to stimulate glucose and lipids uptake and oxidation in target tissues as liver (Bugianesi et al. 2005b). Our data show that insulin treatment improves fasting glycemia, insulin resistance indexes, free fatty acids, and HDL-cholesterol. However, insulin treatment does not improve CRP, adiponectin and liver lipids, and inflammatory markers. Recent data showed that insulin is not able to improve circulating adiponectin and CRP levels in diabetic mice and in type 2 diabetes patients (Aas et al. 2006; Fujita et al. 2005). Insulin can partially reduce portal inflammation, although it does not significantly decrease liver inflammatory markers. Insulin is not able to improve systemic oxidative stress markers, but a significant decrease of the same markers in hepatic tissue is observed, showing that it can be useful in reducing liver oxidative stress, a major feature of NAFLD.

Atorvastatin is commonly prescribed as a non-HDL cholesterol-decreasing agent. In agreement with previous studies, atorvastatin significantly increases HDL cholesterol and decreases free fatty acids (Bayés et al. 2005; Hernandez 
Fig. 5 Liver protein carbonyl (nmol/ mg protein) (a) and free 8-isoprostane (ng/ mg protein) (b) in treatments and high-fat diet groups. $A D$ atherogenic diet, $A D I$ $\mathrm{AD}+$ insulin, $A D A \mathrm{AD}+$ atorvastatin, $A D A I \mathrm{AD}+$ atorvastatin plus insulin ( $n=8-9$ per group). Data are presented as means \pm SEM. *Represents a significant difference from $\mathrm{AD}$ group $(* P<$ 0.05). ${ }^{\$}$ Represents a significant difference from atorvastatin group $\left({ }^{\$} P<0.05\right)$
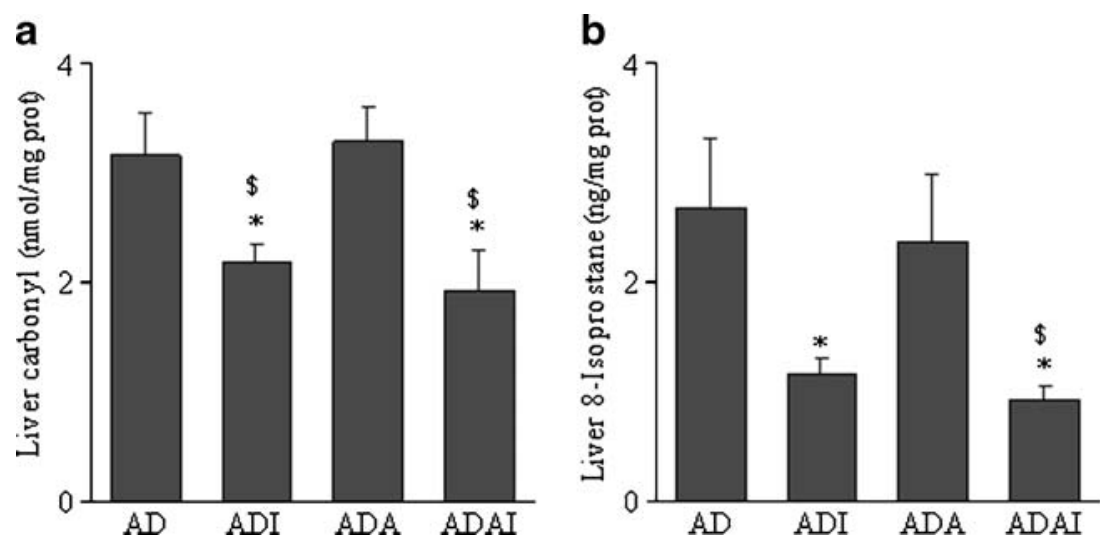

et al. 2006; Shetty et al. 2004). Until now, many studies have been done in order to test whether statins can improve inflammatory status and glucose homeostasis besides the lipid profile. Furthermore, the acute and chronic effects of statins are not fully elucidated. Recent data showed that statins have no effect on CRP levels or other inflammatory markers (Bayés et al. 2005; Lam et al. 2006), or if so, it was used in a concentration fivefold higher than the one used in our study, exceeding the concentrations used in clinical practice (Wong et al. 2006). In another recent study, simvastatin had acute CRP-lowering properties, but this effect decreased with time, returning circulating CRP levels to baseline values (Hernandez et al. 2006). In our study, we show that atorvastatin ( $10 \mathrm{mg} \mathrm{kg}^{-1}$ day $^{-1}$ during 30 days $)$ is not able to significantly decrease CRP levels.
It was observed that atorvastatin has no effect on insulin resistance in dyslipidemic patients (Bayés et al. 2005). Satoh et al. (2005) showed that atorvastatin has no effect in glucose tolerance in normal GK rats, and in this study, we show that atorvastatin is also unable to improve glycemia $2 \mathrm{~h}$ after a glucose load in a context of hyperlipidemia in the same animal model. However, in our study, atorvastatin can improve insulin resistance indexes, although in a lesser extent to that of insulin and combination treatment.

Our data also show that atorvastatin lower adiponectin levels, which is an unexpected effect, since previous studies showed that atorvastatin has no effect on circulating adiponectin levels in diabetic patients (Bayés et al. 2005; Shetty et al. 2004). However, a recent study from Forst et al. (2007) reported that simvastatin treatment resulted in
Fig. 6 Liver tissue of standard diet (a) and high-fat diet rats (b, c). Arrows indicate portal inflammation, higher in $\mathrm{AD}$ group. $S D$ standard diet, $A D$ atherogenic diet. Hematoxylin$\operatorname{eosin}(\times 100)$

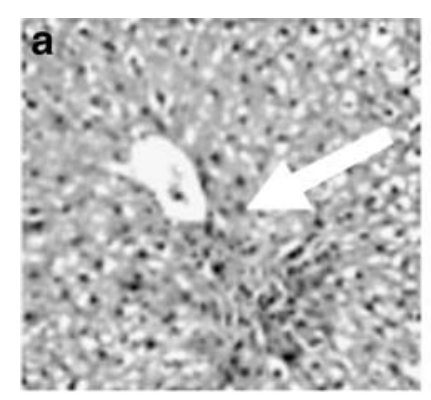

SD 100X

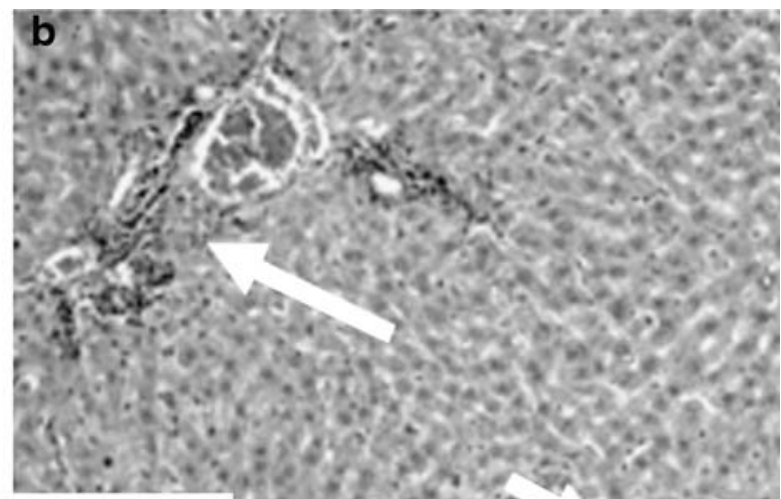

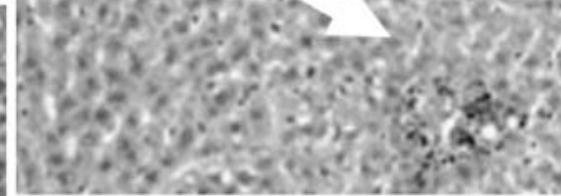

AD 100X

AD 100X 
Fig. 7 Treatments groups in comparison to high-fat diet group. Arrows indicate portal inflammation, lower in treatments groups, namely ADAI group. a $\mathrm{AD}$ atherogenic diet; $\mathbf{b}$ $A D I \mathrm{AD}+$ insulin; c $A D A \mathrm{AD}+$ atorvastatin; d $A D A I \mathrm{AD}+$ atorvastatin plus insulin. Hematoxylin-eosin $(\times 100)$

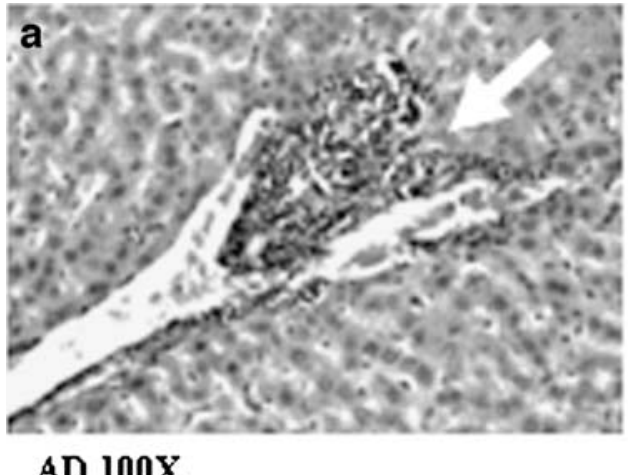

AD $100 \mathrm{X}$

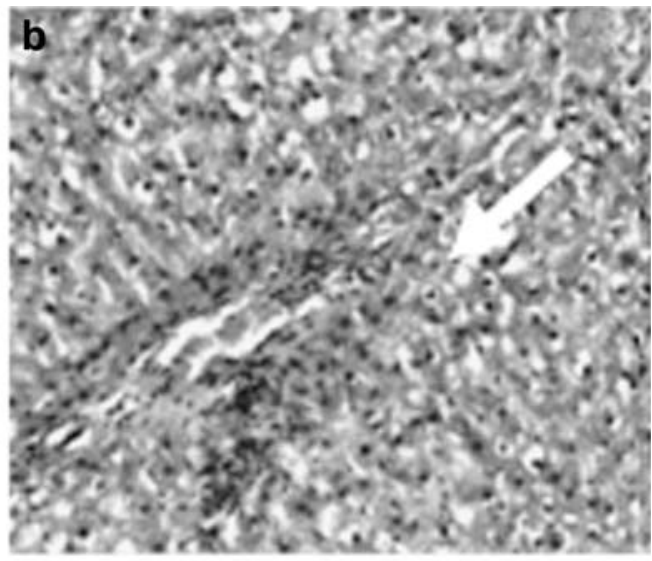

ADI $100 \mathrm{X}$

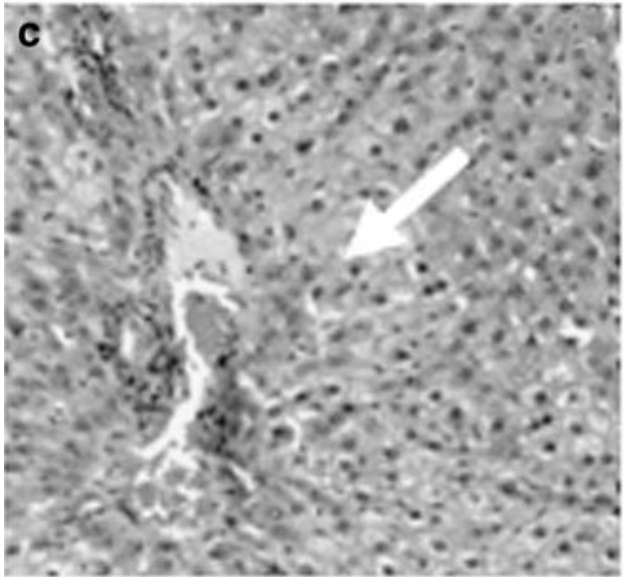

ADA 100X

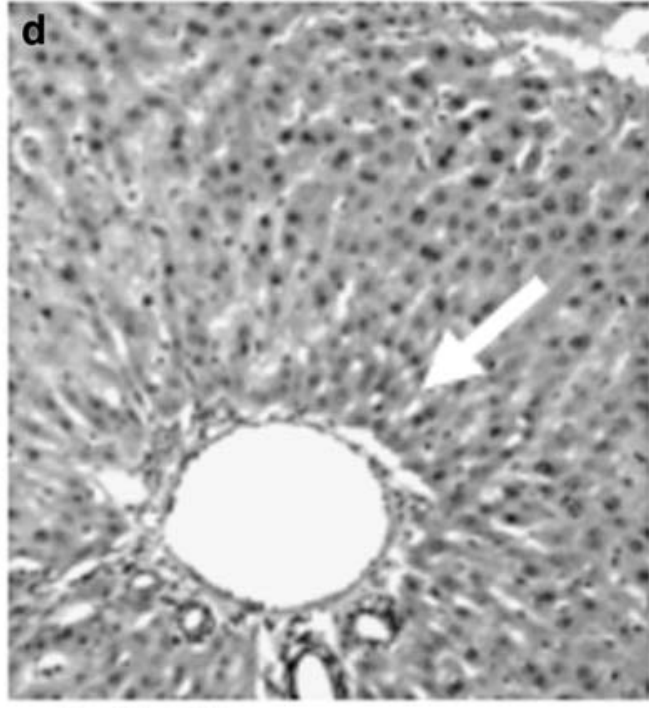

ADAI 100X adiponectin decrease in a non-diabetic population, and Mäuser et al. (2007) showed that atorvastatin decreases adiponectin synthesis in mature adipocytes, which may explain our data. Our results reopen the question about the interactions between atorvastatin and adiponectin.

Atorvastatin was not able to significantly reduce hepatic lipids concentration and oxidative and inflammatory markers in liver. However, histological analysis showed that atorvastatin could partially reduce the degree of liver portal inflammation.

Although individual insulin and atorvastatin reduced HOMA and QUICKI, insulin combination therapy further improves these indexes. The combination of atorvastatin and insulin also led to better glucose tolerance: Only treatments in combination are able to improve glycemia $2 \mathrm{~h}$ after a glucose load. As mentioned, atorvastatin decreases circulating adiponectin levels when administered isolated, but this effect is no longer observed when administered in combination with insulin. Only treatments in combination are able to reduce atherogenicity index, CRP circulating levels, and liver TNF- $\alpha$ and IL-6 levels. Similar results are obtained with histological analysis: Unlike individual therapies, therapeutic combination results in a marked reduction of inflammation in comparison to the high-fat diet group.

Our data show that whole body oxidative stress is not altered by the treatment combination. However, liver protein carbonyl and free 8-isoprostane levels are significantly diminished by insulin and combination treatment, suggesting that insulin has a marked role in decreasing liver oxidative stress and that atorvastatin can enhance it.

Current treatment of non-alcoholic hepatic steatosis underlies weight loss (Comar and Sterling 2006; Federico et al. 2006; Forst et al. 2007; Mäuser et al. 2007). Primary therapies act over lipids and glucose homeostasis in order to reduce insulin resistance. Available therapeutic options include antioxidants, insulin sensitizers, hepatoprotectants, and lipid-lowering drugs (Federico et al. 2006; Mäuser et al. 2007). However, specific treatments are not established due to the absence of randomized and controlled clinical trials (Federico et al. 2006). 
Recent standards in medical care suggest insulin therapy in early stages of type 2 diabetes due to its effects in lowering insulin resistance (Zhou et al. 2005). However, insulin effectiveness in hepatic injuries is not elucidated. This study suggests that insulin can have beneficial effects in liver, namely in oxidative stress improvements. The usefulness and safety of statins in the liver was recently demonstrated in NAFLD patients through improvements in progression to liver fibrosis, hepatic aminotransferases, and liver lipid levels (Ekstedt et al. 2007; Georgescu and Georgescu 2007; Gómez-Domínguez et al. 2006). In a randomized study enrolling NAFLD patients, Athyros et al. (2006) observed that atorvastatin produced better results than fenofibrate in improving NAFLD and in ameliorating circulating CRP and lipid levels. Our data show that atorvastatin and insulin, by itself, have no major effects in hepatic injury associated with type 2 diabetes with hyperlipidemia. However, therapy combination produces, in this animal model, improvements in liver inflammatory and oxidative stress parameters beyond their individual components. These results offer important mechanistic data which reinforce the usefulness of this combination therapy in improving metabolic profile and protecting liver in type 2 diabetes with hyperlipidemia.

Acknowledgments This work was supported by University of Coimbra and University Hospitals of Coimbra. We tank SERVIER Portugal for financial support. We thank Prof. João Patrício and coworkers (Lurdes Silva, Carlos Silva and José Pedro Relvão) from the Animal Research Center Laboratory, University Hospitals, Coimbra for all the help in maintaining the animals. We thank Serviço de Patologia Clínica from the University Hospital of Coimbra for the technical support. We thank Mário Simões for his technical support.

\section{Potential conflict of interests Nothing to report.}

\section{References}

Aas A, Seljeflot I, Torjesen P, Diep L, Thorsby P, Birkeland K (2006) Blood glucose lowering by lifestyle intervention has different effects on adipokines as compared with insulin treatment in subjects with type 2 diabetes. Diabetologia 49:872-880

Athyros V, Mikhailidis D, Didangelos T, Giouleme O, Liberopoulos E, Karagiannis A et al (2006) Effect of multifactorial treatment on non-alcoholic fatty liver disease in metabolic syndrome: a randomised study. Curr Med Res Opin 22:873-883

Bayés B, Granada ML, Lauzurica R, Pastor MC, Navarro M, Bonet J, Llopis MA, Romero R (2005) Effect of low doses of atorvastatin on adiponectin, glucose homeostasis, and clinical inflammatory markers in kidney transplant recipients. Transplant Proc 37:3808-3812

Bisgaier C, Essenburg A, Auerbach B, Pape M, Sekerke C, Gee A, Wölle S, Newton R (1997) Attenuation of plasma low density lipoprotein cholesterol by select 3-hydroxy-3-methylglutaryl coenzyme A reductase inhibitors in mice devoid of low density lipoprotein receptors. J Lipid Res 38:2502-2525
Bradbury M (2006) Lipid metabolism and liver inflammation. Am J Physiol Gastrointest Liver Physiol 290:G194-G198

Brownlee M (2005) The pathobiology of diabetic complications. Diabetes 54:1615-25

Bugianesi E, Gastaldelli A, Gambino R, Cassader M, Baldi S, Ponti V, Pagano G, Ferrannini E, Rizzetto M (2005a) Insulin resistance in non-diabetic patients with non-alcoholic fatty liver disease: sites and mechanisms. Diabetologia 48:634-642

Bugianesi E, McCullough A, Marchesini G (2005b) Insulin resistance. Hepatology 42:987-1000

Cave M, Deaciuc I, Mendez C, Song Z, Joshi-Barve S, Barve S, McClain C (2007) Nonalcoholic fatty liver disease: predisposing factors and the role of nutrition. J Nutr Biochem 18:184-195

Chen H, Sullivan G, Quon MJ (2005) Assessing the predictive accuracy of QUICKI as a surrogate index for insulin sensitivity using a calibration model. Diabetes 54:1914-1925

Chrysohoou C, Pitsavos C, Skoumas J, Masoura C (2006) The emerging anti-inflammatory role of HDL-cholesterol, illustrated in cardiovascular disease free population, the ATTICA Study. Int J Cardiol 122:29-33

Comar K, Sterling R (2006) Review article: drug therapy for nonalcoholic fatty liver disease. Aliment Pharmacol Ther 23:207-215

Davidson M (2005) Reducing residual risk for patients on statin therapy: the potential role of combination therapy. Am J Cardiol 96:3K-13K

Ekstedt M, Franzén L, Mathiesen U, Holmqvist M, Bodemar G, Kechagias S (2007) Statins in non-alcoholic fatty liver disease and chronically elevated liver enzymes: a histopathological follow-up study. J Hepatol 47:135-141

Federico A, Trappoliere C, Loguercio C (2006) Treatment of patients with non-alcoholic fatty liver disease: current views and perspectives. Dig Liver Dis 38:789-801

Forst T, Pfützner A, Lübben G, Weber M, Marx N, Karagiannis E et al (2007) Effect of simvastatin and/or pioglitazone on insulin resistance, insulin secretion, adiponectin, and pro-insulin levels in nondiabetic patients at cardiovascular risk-the PIOSTAT Study. Metabolism 56:491-496

Fujita H, Fujishima H, Koshimura J, Hosoba M, Yoshioka T, Shimotomai $\mathrm{T}$ et al (2005) Effects of antidiabetic treatment with metformin and insulin on serum and adipose tissue adiponectin levels in $\mathrm{db} / \mathrm{db}$ mice. Endoc J 52:427-433

Georgescu E, Georgescu M (2007) Therapeutic options in nonalcoholic steatohepatitis (NASH). Are all agents alike? Results of a preliminary study. J Gastrointest Liver Dis 16:39-46

Gómez-Domínguez E, Gisbert JP, Moreno-Monteagudo JA, GarcíaBuey L, Moreno-Otero R (2006) A pilot study of atorvastatin treatment in dyslipemic, non-alcoholic fatty liver patients. Aliment Pharmacol Ther 23:1643-1647

Grimsrud P, Picklo M, Griffin T, Bernlohr D (2007) Carbonylation of adipose proteins in obesity and insulin resistance: identification of adipocyte fatty acid-binding protein as a cellular target of 4hydroxynonenal. Mol Cell Proteomics 6:624-37

Hanley A, Williams K, Festa A, Wagenknecht L, D’Agostino R, Haffner S (2005) Liver markers and development of the metabolic syndrome. Diabetes 54:3140-3147

Hernandez T, Capell W, Wolfe P, Gerard L, Eckel R (2006) Time course of C-reactive protein reduction with simvastatin therapy in patients with type 2 diabetes mellitus. Am J Cardiol 98:16561659

Kaneto H, Matsuoka T, Nakatani Y, Kawamori D, Miyatsuka T, Matsuhisa M, Yamasaki Y (2005) Oxidative stress, ER stress and the JNK pathway in type 2 diabetes. J Mol Med 83:429-439

Lam H, Chu C, Wei M, Keng H, Lu C, Sun C et al (2006) The effects of different doses of atorvastatin on plasma endothelin-1 levels in type 2 diabetic patients with dyslipidemia. Exp Biol Med 231:1010-1015 
Ludwig S, Dharmalingam S, Erickson-Nesmith S, Ren S, Zhu F, Ma $G$ et al (2005) Impact of simvastatin on homeostatic and fibrinolytic regulators in type 2 diabetes mellitus. Diabetes Res Clin Pract 70:110-118

Maeda K, Cao H, Kono K, Gorgun C, Furuhashi M, Uysal K et al (2005) Adipocyte/macrophage fatty acid binding proteins control integrated metabolic responses in obesity and diabetes. Cell Metab 1:107-119

Makowski L, Hotamisligil G (2005) The role of fatty acid binding protein in metabolic syndrome and atherosclerosis. Curr Opin Lipidol 16:543-548

Maseri A (1995) In: Maseri A (ed) Ischemic heart disease. Churchill Livingstone, New York, $\mathrm{p} 713$

Mäuser W, Perwitz N, Meier B, Fasshauer M, Klein J (2007) Direct adipotropic actions of atorvastatin: differentiation state-dependent induction of apoptosis, modulation of endocrine function and inhibition of glucose uptake. Eur J Pharm 564:37-46

Meier U, Gressner A (2004) Endocrine regulation of energy metabolism: review of pathobiochemical and clinical chemical aspects of leptin, ghrelin, adiponectin and resistin. Clin Chem 50:1511-1525

Neuschwander-Tetri B (2005) Nonalcoholic steatohepatitis and the metabolic syndrome. Am J Med Sci 330:326-335

Nunes E, Peixoto F, Louro T, Sena CM, Santos MS, Matafome P, Moreira PI, Seiça R (2007) Soybean oil treatment impairs glucose-stimulated insulin secretion and changes fatty acid composition of normal and diabetic islets. Acta Diabetol 44:121-130

Ota T, Takamura T, Kurita S, Matsuzawa N, Kita Y, Uno M et al (2007) Insulin resistance accelerates a dietary rat model of nonalcoholic steatohepatitis. Gastroenterology 132:282-293

Paumelle R, Blanquart C, Briand O, Barbier O, Duhem C, Woerly G et al (2006) Acute anti-inflamatory properties of statins involve peroxissome proliferator-activated receptor- $\alpha$ via inhibition of the protein kinase C signalling pathway. Circ Res 98:361-369

Pfützner A, Forst T (2006) High-sensitivity C-reactive protein as cardiovascular risk marker in patients with diabetes mellitus. Diabetes Technol Ther 8:28-36

Planavila A, Juan L, Vásquez-Carrera M (2005) Atorvastatin improves peroxisome proliferator-activated receptor signaling in cardiac hypertrophy by preventing nuclear factor-kappaB activation. Biochim Biophys Acta 1687:76-83

Satoh K, Keimatsu N, Kanda M, Kasai T, Takaguri A, Sun F, Ichihara K (2005) HMG-CoA reductase inhibitors do not improve glucose intolerance in spontaneously diabetic Goto-Kakizaki rats. Biol Pharm Bull 28:2092-2095

Seiça RM, Suzuki KI, Santos RM, Rosário LM (2004) Deficiência primária da secreção de insulina de ilhéus isolados de ratos Goto-Kakizaki, um modelo animal de diabetes tipo 2 não obesa. Acta Med Port 17:42-48

Sethi J, Hotamisligil G (1999) The role of TNF $\alpha$ in adipocyte metabolism. Sem Cell Dev Biol 10:19-29

Shang W, Yasuda K, Takahashi A, Hamasaki A, Takehiro M, Nabe $\mathrm{K}$ et al (2002) Effect of high dietary fat on insulin secretion in genetically diabetic Goto-Kakizaki rats. Pancreas 25:393-399

Shetty G, Economides P, Horton E, Mantzoros C, Veves A (2004) Circulating adiponectin and resistin levels in relation to metabolic factors, inflammatory markers, and vascular reactivity in diabetic patients and subjects at risk for diabetes. Diabetes Care 27:2450 2457

Shoelson S, Herrero L, Naaz A (2007) Obesity, inflammation, and insulin resistance. Gastroenterology 132:2169-2180

Wong V, Stavar L, Szeto L, Uffelman K, Wang C, Fantus G, Lewis G (2006) Atorvastatin induces insulin sensitization in Zucker fatty rats. Atherosclerosis 184:348-355

Yamauchi T, Kamon J, Ito Y, Tsuchida A, Yokomizo T, Kita S et al (2003) Cloning of adiponectin receptors that mediate antidiabetic effects. Nature 423:762-769

Yki-Järvinen H (2005) Fat in liver and insulin resistance. Ann Med $37: 347-356$

Yoneda M, Iwasaki T, Fujita K, Inamori M, Nozaki Y, Maeyama S et al (2007) Hypoadiponectinemia plays a crucial role in the development of nonalcoholic fatty liver disease in patients with type 2 diabetes mellitus independent of visceral adipose tissue. Alcohol Clin Exp Res 31:15S-21S

Zhou H, Song X, Briggs M, Violand B, Salsgiver E, Luo Y (2005) Adiponectin represses gluconeogenesis independent of insulin in hepatocytes. Biochem Biophys Res Commun 338:793-799 